\section{Motsamai \\ Molefe}

Dr M Molefe, School of

Religion, Philosophy

and Classics, Ethics

Studies, University of

KwaZulu Natal, New

Arts Building, Golf

Road, Pietermaritzburg

Campus; E-mail:

molefem@ukzn.ac.za

DOI: http://dx.doi.

org/10.18820/24150479/

aa48i1.5

ISSN: ISSN 0587-2405

e-ISSN: 2415-0479

Acta Academica $\cdot 2016$

48(1): 91-110

(c) UV/UFS

\title{
A critique of Kwasi Wiredu's humanism and impartiality
}

This article offers a critical reflection on Kwasi Wiredu's moral theory. On the one hand, the article is concerned with the meta-ethical question regarding the nature of moral properties, specifically, whether they are physical (natural) or spiritual (supernatural). On the other, I reflect on one facet of Wiredu's normative theory, namely, whether morality is best captured by partiality or impartiality in the African tradition. With regards to meta-ethics, this article reflects that Wiredu's rejection of a spiritual (supernaturalist) foundation of African ethics is unsatisfactory; I also contend that he does not offer a satisfactory defence of physicalism. I conclude by observing that a plausible meta-ethical theory, either physicalist or religious, is yet to be elaborated within the African tradition. Secondly, I argue that Wiredu's normative theory is characterised by a feature - impartiality - that is at odds with much of African moral intuitions. Assertions like 'charity begins at home' seem to suggest that African ethics should be read in terms of partiality rather than impartiality. 


\section{Introduction}

The anthology Person and Community: Ghanaian Philosophical Studies $1^{1}$ was a ground-breaking intellectual project that played a huge role in exposing the world of philosophy to topics in African philosophy. Three salient philosophical contributions caught the attention of readers: Kwame Gyekye's statement of an under-explored conception of democracy qua consensus (1992: 243-256); Gyekye's influential moral-political theory of 'moderate communitarianism' - a defence of human rights (1992: 101-123); and Kwasi Wiredu's moral theory of 'sympathetic impartiality' (1992: 193-206). The first two philosophical accounts have received some considerable critical engagement in the literature; ${ }^{2}$ the latter, however, has not received as much critical attention. ${ }^{3}$ I reject two aspects of Wiredu's moral theory, namely: firstly, I problematise humanism - a secular interpretation of morality that dominates African moral theorisation - a thesis that human nature is a source and foundation of (all) moral value; secondly, I reject Wiredu's interpretation of morality in terms of sympathetic impartiality insofar as it departs from the evidence that recommends partiality as the best interpretation of African ethics.

Wiredu's ethical theory has previously been subjected to critical consideration. Thad Metz, an expert of Ubuntu, critically discusses Wiredu's moral theory of sympathetic impartiality as an instance of utility in African moral discourse, but does not give a detailed account as to the nature of the 'utility' in question; he simply assumes that it is more or less the same as the Western utilitarian account (2007: 330). Metz has also criticised Wiredu's impartialism and rejects the golden rule as indeterminate as a principle of right action (Metz 2013: 151,156). I offer a more extensive critique here by drawing on the African tradition to support partiality. More recently, Okeja applies sympathetic impartiality to a quest for a global ethic, but does not give an extensive critical engagement of this theory (2013).

1 This is a book that was edited by Kwame Gyekye and Kwasi Wiredu.

2 Many scholars have thrown their bones into the claim that Africans do not generally adhere to a democracy that is a based on the principle of majoritarianism; rather, they favour one that is grounded on the value of consensus (See Wamala, 2004; Teffo, 2004; Wingo, 2004; Wiredu, 1996; Ramose, 1992; 2009: Metz, 2012). Further, Gyekye's moral-political theory, 'moderatecommunitarianism' has shaped and influenced debates in the African moral-political discourse for over 20 years; no account, I observe, has received as much attention in the literature. This discussion was fuelled by a keen interest many scholars took in the debate between Ifeanyi Menkiti and Kwame Gyekye on the issue of 'personhood'. I here only bring to attention three critical engagements that I find most interesting in the literature (See, Manyeli, 2010: no pages; Metz, 2012: 61-83; Metz, 2013: 141-162).

3 I comment on this fully in the next paragraph 
My critique of Wiredu's moral theory will focus on his humanism and impartiality. I challenge humanism precisely because I hold the intuition that African ethics is best captured by appeal to some religious consideration following the thinking of John Mbiti (and others) (Mbiti, 1970; Louw, 2004). Here, I will be content merely to demonstrate that Wiredu has not provided us with a good philosophical reason for believing that morality cannot be grounded on religious considerations or that it ought to be grounded on physical ones. With regards to impartiality, I argue that African moral intuitions like 'charity begins at home' appears to imply that morality in African thought may best be captured in terms of partiality, a moral consideration that is at odds with Wiredu's moral principle of 'sympathetic impartiality'.

This article proceeds as follows. Firstly, I briefly familiarise the reader with Wiredu's meta-ethical position, humanism. Secondly, I consider Wiredu's 'welfarism', and I also make a rough sketch of how an African theory of welfare might look: welfare qua needs fulfilment. In the third section, I illuminate Wiredu's principle of right action qua sympathetic impartiality in the form of the golden rule. And, finally, I proceed to criticise Wiredu's moral theory. Firstly, I problematise his humanism and secondly, his impartialism.

In giving the reader a sense of Wiredu's moral theory, it is crucial that I be clear about what I mean with the notions 'moral theory' or 'ethics'. Christine Korsgaard distinguishes three senses a philosopher might have in mind when dealing with moral theorisation (1983: 169). Firstly, one could be after a principle of right action (normative theorisation). Here a philosopher specifies a ground norm or a principle that specifies what all im/permissible actions have in common - a theory of right action. Secondly, one could be after an answer to the question 'what makes a life go well?' In this sense, one is looking for that property in virtue of which life will be considered choiceworthy. Lastly, one could simply be concerned about questions of what is a good character. For the purposes of this analysis, I will limit myself to the first sense of moral theorisation i.e. a theory of right action. In what follows, I give the reader a sense of Wiredu's meta-ethical theory and afterwards, I procced to discuss his normative theory.

\section{Wiredu's humanism}

By 'meta-ethics' I mean an account about the nature of moral properties, whether they are physical or spiritual. ${ }^{4}$ To claim that moral properties are 'physical' amounts to the position that physical properties are natural and as such can

4 I will not here consider 'non-naturalism' since there is no one who defends such a view in the (African) literature. 
be accessed by appeal to scientific methods. To claim that moral properties are 'spiritual' amounts to the claim that they are supernatural and as such one has to rely on methods that are beyond science, such as intuitions. Wiredu for his part holds the view that the best way to understand morality in the African tradition is in terms of some physical property. He denies that morality can be grounded on any spiritual foundation and therefore argues that "the will of God, not to talk of that of any other extra-human being, is logically incapable of defining the good (Wiredu 1992: 194).

Elsewhere, he explicitly states: "But in fact, I deny that Akan moral thought is supernaturalistic to any extent" (1996: 234). This means that, morality cannot be grounded in any supernaturalistic considerations or properties. To say that morality cannot be grounded in spiritual considerations does not mean that God and ancestors play no role at all; it is rather to deny that this role may be foundational. Hence, it is common then that extra-human entities can be considered to play a supportive role (Wiredu, 1996: 239, See also Gyekye, 2010). This role is generally exemplified in taboos that appeal to some extra-human authority. Even in this light, Wiredu insists that these taboos can be explained purely in rational terms (1996: 237-238).

Wiredu refers to his naturalistic ethics in terms of 'humanism'. In other words, the physical property that grounds or informs morality is some aspect of human nature. He articulates his humanism by appeal to his native (Akan) language 'Onipa na ohia'. He translates this sentence to mean "that it is a human being that has value" and observes that the original language is more illuminating than English:

The word "(o)hia" in this context means both that which is of value and that which is needed. Through the first meaning the message is implied that all value derives from human interests and through the second that human fellowship is the most important of human needs (1992: 194).

Elsewhere he observes that "the first axiom of all Akan axiological thinking is that man or woman is the measure of all value" (1996: 65).

The first meaning is crucial in terms of capturing Wiredu's meta-ethics. All moral value, according to him, is a function of human nature, specifically, human interests. We can only derive morality from some facts connected with human beings or their interests. Simply put, 'humanism' is the doctrine that some aspect of human nature is the source and foundation of all moral value; and by implication without humanity there would be no morality. It is therefore fitting that his metaethical position is captured as humanistic and not supernaturalistic. 


\section{Wiredu's theory of right action}

To articulate Wiredu's principle of right action, I begin by clarifying how Wiredu understands morality. Wiredu talks about strict morality and he contrasts it with custom, and sometimes he refers to this distinction in terms of ethics, moral philosophy proper, and an ethic, custom (Wiredu, 1992, 1996a, 1996b, $2005,2008)$. The latter, custom, is concerned with questions of human interaction at a contingent level, and is not universal and can change over time (1996: 237). An ethic or custom is concerned with questions of how to raise children, rules regarding weddings and married life, how to bury the dead, greetings and so on (Wiredu, 2005; 2008). Strict morality, on the other hand, offers principles that inform human interaction that is both essential and universal, without which human existence is in jeopardy. He characterises strict moral rules as "intrinsically obligatory" (1996: 65). So, an ethic may recommend that people should not eat with their hands and an ethics requires that people be truthful. The choice of whether people eat with their hands, spoons or whatever kind of utensil does not threaten the continuance and quality of life. But if people were to abandon the institution of honesty and truth as a matter of accepted norm, the whole human project would be threatened (Wiredu, 1992; 2005; 2008). We may now enquire as to the basic norm that grounds morality according to Wiredu.

It is safe, I contend, to construe Wiredu's moral theory in terms of welfare or that it defends some version of welfarism. 'Welfarism' is the claim that well-being "is the only value which an ethical theory needs to take seriously, ultimately and for its own sake" (Sumner, 1996: 3). For example, Wiredu, in his very first articulation of his moral theory, claims that "by our lights, human well-being is an irreducible presupposition of all morality ... every moral endeavour is a certain kind of quest after human well-being" (Wiredu, 1996: 64). And he continues to claim that "[e]very Akan maxim about the specifically moral views that I know ... postulates the harmonization of interests as the means, and the securing of human well-being as an end, of all moral endeavour" (Wiredu, 1996: 65).

Wiredu's reference to well-being as an irreducible proposition of all morality implies that it is a foundational or basic norm upon which all morality is grounded. In other words, it is a fundamental moral property against which we can assess moral actions or characters. One can safely assume that since it is fundamental or basic, all other values reduce to it. In other words, freedom or equality are good because they lead to well-being. Wiredu's language of capturing well-being as an end and harmonisation of interests as a means also captures his welfarism. To refer to well-being as an end is to claim that it is a final good, the very essence or goal of morality; in other words, actions are right or wrong insofar as they produce or lead to well-being or wrong if they detract from it. 
It is not entirely clear whether Wiredu is using the phrases 'human well-being' and 'human interests' as interchangeable or whether he thinks that satisfaction of human interests leads to welfare (Wiredu, 1992: 194 \& Wiredu, 1996: 65; 2004: 18). Either way, this does not quite help us to understand what Wiredu has in mind when he talks about well-being. This consideration is crucial given that Wiredu does not tell us what he means by either well-being or by human interests. This lack of conceptual and theoretical clarity and elaboration does not help the case of moral philosophising in the African tradition. Clarity with regards to welfarism, what he considers to constitute human well-being, is crucial for Wiredu since lack thereof has the potential to cast in a negative light an otherwise promising account because much of 'welfarism' as captured in terms of utilitarianism has not had a good philosophical record; it thus becomes urgent for a philosopher to distinguish his kind of welfarism (Kylmicka, 1990).

I admit that Wiredu is not alone in being vague about what he means by wellbeing. I am not aware of any thoroughgoing account of welfare in the African tradition. ${ }^{5}$ I do however think that in the light of certain claims made by African scholars, in general, and, Wiredu specifically, it is justified to construe welfare in terms of basic human needs fulfilment (Gyekye, 1992; 2004; Wiredu, 1992; 2008; Metz, 2007). A close reading of Wiredu strongly suggests that he conceives of well-being in these terms. Two aspects of Wiredu's humanism in particular support the argument that he conceives of welfare in terms of basic human needs fulfillment. First, the centrality of needs emerges from the fact that human beings are conceived as essentially and continuously self-insufficient; secondly, I deduce the centrality of needs from the imagery of the siamese crocodile. This figure - typically invoked in Akan moral thought - with two heads and one stomach underscores the need for harmony as central to social existence.

Remember, Wiredu articulates his humanism by appeal to an Akan adage that has dual meanings. This Akan adage reveals two aspects of human nature. On the one hand, a human being, individually, is characterised as a bearer of moral value; and, on the other, she is characterised by natural inadequacy that necessitates human fellowship. A human being is understood simultaneously as a being of value and of need. An insight that flows from this adage is that though a human being is a bearer of value, she, however, requires the context of a robust human interaction to develop her full humanity. Human fellowship, it is correct to suppose, is essential for her functioning as an ordinary human being. In light of the human inadequacy mentioned above, it is not surprising to read:

5 The closest text that approximates this task is entirely unsatisfactory, as it heavily leans on the Western paradigm (Gyekye, 2004: 40 - 50). 
Self-reliance is of course understood and recommended by the Akans, but its possibility is predicated upon this ineliminable residue of human dependency. Human being's, therefore, at all times ... need the help of their kind (Wiredu, 1998: 293).

The idea here is that a human being individually is continually and essentially insufficient to the task of survival, personal development and moral development. This natural insufficiency of a human being positions her as one who always stands in need of the help of fellow human beings. One interesting consequence that follows from this thought is that it completely repositions how one may think about self-interest. It appears that a moral theory entailed in this account cannot cohere with anything like ethical egoism. On this account, to truly talk of selfinterest is to always implicate one in relation with others between whom there is always (an essential) co-dependency. ${ }^{6}$ So much so that without these relations, one's sense of self both descriptively and normatively would be compromised and unfortunate. So, in this sense, I need other human beings to discover myself as a human being, to function ordinarily as a human being and to flourish as a moral agent.

The second clue is found in one of the profound ethical symbols in the Akan culture of a crocodile with two heads and one stomach (Wiredu, 1992; 1996). Wiredu invokes this art motif to elaborate on his moral philosophy (Wiredu, 1998: 290). I think it is also instructive of needs as a central tenet to this notion of well-being. In this line, human being's at bottom have the same interests (one stomach), and without finding ways to balance or adjust conflicts, the human society is jeopardy. So, the stomach represents their needs to survive or function. So, this ethical symbolism communicates needs.

Further, African scholars have observed that African moral thought is grounded in duties that are best explicable by appeal to needs rather than to rights as is the case typically in the West. For example, Thad Metz, in his ground-breaking paper on African ethics, captures the following intuition as salient below the Sahara:

a greater percentage of Africans think that one is morally obligated to help others, roughly to the extent that one can and that others need, with rights not figuring into the analysis of how much one ought to transfer wealth, time or labour (Metz, 2007: 326).

$6 \quad$ I here bring to the attention of the reader the distinction between contingently shared relations and essentially shared relations (Neal et al. 1990: 425-430). I observe the relations involved here are of the latter kind. So much that we are told that "The idea of dependency may even be taken as a component of the Akan conception of a person" (Wiredu, 1992: 201). 
Kwame Gyekye, a fellow Ghanaian African philosopher and former colleague of Wiredu at the University of Ghana also understands African thought to be grounded in the notion of needs rather than rights. He observes that "A shared humanity, conceived as a universal family of humankind, mandates, not a rightsbased morality [...] it mandates rather a kind of moral outlook animated by the awareness of the needs and interests of others and demonstration of sensitivity to those needs (Gyekye 2004: 91, emphasis mine; see also Donnelly, 1982; Menkiti, 1984; Masolo, 2004; Wiredu, 2008). The view from these scholars is that Afro-communitarian societies are not rights-based, but may be understood as based on duties that are responsive to others' needs. So, there is some agreement among African scholars that well-being is a function of fulfilling human needs. It is for this reason that African ethics is sometimes compared to or even captured in terms of care (Ramose, 2009; Metz, 2012).

Thus far, we have made sense of Wiredu's humanism, and we have proceeded to elaborate on what he considers to be the ultimate good, welfarism qua human needs fulfilment. I proceed now to focus on his principle of right action. Wiredu calls this principle sympathetic impartiality, which he understands to be tantamount to the golden rule (Wiredu, 1992: 194 \& 198; 1996: 29, 41 \& 170). This principle functions, it appears, to harmonise or adjust human interests to the effect of securing human well-being. Why do human interests need to be adjusted or harmonised? The reason is found in the art motif of a crocodile with two heads alluded to above. A message that is communicated by the two heads is the idea "although human beings have a core of common interests, they also have conflicting interests that precipitate real struggles ... the aim of morality $\ldots$ is to harmonize those warring interests through systematic adjustment and adapting" (1992: 197).

We should remember that Wiredu informed us that harmonisation of interests is the means and the goal is the securing of well-being. So, "harmonisation of human interests' is operationalised by appeal to the golden rule and it is meant to ultimately lead to well-being. So, we may ask: how does Wiredu make sense of the golden rule?

Wiredu gives several articulations of how he understands the golden rule. In some instances, he represents it positively: "Let your conduct at all times manifest a due concern for the interests of others ... a person may be said to manifest a due concern for the interests of others if in contemplating the impact of his actions on their interests, she puts herself imaginatively in their position" (Wiredu, 1996: 31). And in some, negatively: "Do not do unto others what you would not that they do to you" (Wiredu, 1992: 198, see also 1996: 41). It is also important to note that Wiredu equates the golden rule to what he refers to as 
sympathetic impartiality (Wiredu, 1996: 170). Wiredu informs us that the principle of sympathetic impartiality requires us to "be willing to put oneself, as the saying goes, in the shoes of others when contemplating an action" (Wiredu, 1996: 237). In another place, he states: "Pure morality - that is, those requiring of the individual an impartial regard for the interests of others motivated by a certain minimum of altruism - are the most indispensable" (1999: 33). He refers to this principle as a test of what might be permissible or impermissible action. To exemplify how the moral test functions, he evaluates a custom among the Akans that required some people to be killed so as to accompany and continue to serve their departed king in the afterlife. Wiredu notes:

When it is subjected to this test, it is, of course, found wanting. Why so? Because the custom would seem to run counter to the principle of sympathetic impartiality: Would the king himself welcome an identical treatment in an exchange of stations? Most likely not (1996: 240 - 241).

This moral test or principle requires one to impartially imagine oneself in another's position and 'see' whether they would welcome the action or outcome in question. With regards to the king, he should put himself in the position of a servant and consider whether he would be willing to be put to death so as to accompany and serve his king in the afterlife. Wiredu informs us that the king qua servant's position would probably not accept such a position.

It is crucial to note that that this moral theory has two aspects: on the one hand, there is some kind of moral psychology captured either in terms of sympathy/ empathy; and, on the other, there is the element of impartiality. With regards to sympathy (empathy), Wiredu claims that it is "the root of all moral virtue" (Wiredu, 1996: 71). I will not challenge this aspect of the theory. It is the second aspect of impartiality that I will subject to scrutiny, as I think it misses what is at the heart of African thought. Below, I start by critically reflecting on humanism.

\section{Rejection of humanism}

At the level of meta-ethics, humanism remains a stubborn feature of African moral thought (Dzobo, 1992; Gyekye, 1995; 2010; Metz, 2012; Imafidon, 2013). Human-centred axiological approaches like the one advocated by Wiredu are problematic for various reasons. To interpret moral value exlusively in terms of human interests involves an untenable anthropocentrism and may also imply speciesism. Elsewhere I argue that this kind of approach is parochial and chauvinistic (Molefe 2015). In this article, I question Wiredu's meta-ethical presupposition that the foundation of morality is best conceived in physicalist 
terms, namely, as grounded in some human property (humanism) as opposed to some spiritual (religious) considerations. I argue that Wiredu has not offered us convincing philosophical reasons to the effect that physical properties do a better job at accounting for morality than religious (spiritual) considerations in the African tradition. ${ }^{7}$

Wiredu reports that his humanism flows from some Akan adage that says that human beings are bearers of all moral value or implies that all moral value is derivable from human beings. It might be anthropologically true that Akan people do actually believe that all moral value derives from human beings, and surely a philosopher may ground his philosophy in such anthropological moral data. But as philosophers, our task is not just to analyse what some anthropologicalmoral data implies with regards to question of morality; more is needed. It is one thing for some claim to be anthropologically true, but quite another for it to be philosophically plausible. The philosophical standard requires that we demonstrate the veracity of the claim in question that 'human beings are bearers of all moral value'; it is not enough to merely analyse its implication - we need reasons and/or evidence to the effect that what Akans actually believe is philosophically true. The whole enterprise of philosophy, so far as I understand it, is based on subjecting and justifying claims on the basis of rational argumentation.

Unfortunately, like many who advocate humanism, Wiredu does not give us a positive argument to defend humanism (Gyekye, 1995, 2010; Metz, 2012). He simply assumes that merely because it is believed by Akans it must be true. Or, he thinks that by simply arguing that African ethics is not supernaturalistic he can secure the alternative, which is naturalism. But all we have from Wiredu is a supposition and not an argument. He claims that "[o]ne important implication of the founding of value on human interests is the independence of morality from religion in the Akan outlook [...]" (1992: 194). If it is true that morality is strictly definable by an appeal to human interests, it indeed implies a kind of independence between it and religion. But this line of reasoning begs the question: is morality purely grounded in human interests? This more pressing philosophical question is left unattended.

Further, Wiredu makes interesting claims about God. He observes, "On the Akan understanding of things, indeed, God is good in the highest; but his goodness is conceptually of a type with the goodness of a just and benevolent ancestor, only in his case quality and scale are assumed to be limitless" (1992: 194). Wiredu appears to be drawing a conceptual distinction between moral goodness and

7 Elsewhere, I argue that humanism is incompatible with a robust environmental ethics as one would expect from an African moral theory (Molefe, 2015). 
God's goodness. There are two senses of the notion of 'good' at play. One is purely moral and the other is that of God; but unfortunately Wiredu does not undertake any conceptual analysis to distinguish the difference that is at least obvious to him; once again the reader is left to wonder what Wiredu has in mind - such a difference is merely asserted and never demonstrated.

The best Wiredu gives us to sustain the conceptual difference between moral goodness and God's goodness is to claim that the latter's is like that of an ancestor, and this kind of elaboration only obfuscates matters. For a human being to qualify as an ancestor after they die, they should have lived a good life i.e. a life that promoted human interests (Wiredu, 1992; Mkhize, 1999). So, metaphysically, an ancestor in some important sense is a human being who has since joined a higher sphere of existence because of their moral achievements. On the other hand, God does not achieve his goodness; it appears to be a property of his very nature, or so it is commonly believed. Thus, to make sense of the kind of goodness of God in terms of the goodness of ancestors appears to be problematic; the one is acquired and the other is inherent. One question lingers in my mind like a sore thumb why is God's goodness inadequate to ground morality? Is God's goodness distinct or opposed to human goodness?

All I am satisfied to make out in this particular passage is that Wiredu has not demonstrated to us that morality is indeed a function of human nature; and he has not even begun to demonstrate that God cannot ground morality in the African tradition. And, if these observations are true then the question of whether morality is physical or spiritual is still an open question in the African tradition.

\section{Wiredu's impartiality}

I proceed now to present three aspects of African culture that recommend partiality as the best interpretation of an African moral tradition contrary to Wiredu's principle of right action: the high regard usually accorded to the family, ancestor veneration and the normative concept of personhood qua a good person. I will not elaborate on all these cultural items to make my argument; to build a strong case it suffices that I appeal to the notion of personhood, which is a central feature of African moral thought. If impartiality does not cohere with this notion of personhood that will be sufficient grounds to reject it. But for the sake of a non-African audience, I will give a brief discussion of the other two aspects of African culture that also endorse partiality: family and ancestor veneration. 


\subsection{Family and partiality}

Wiredu construes his principle of right action in terms of sympathetic (empathetic) impartiality. This comes with the implication that morality in the African tradition is best construed as impartial. I begin my analysis with how the notion of a family appears to imply partiality.

A family unit is usually accorded a high status, morally speaking, within the African tradition. It is interesting to note that the family is reported as the best school for moral education (Wiredu, 1996: 248). It is also interesting to note that many African scholars articulate their moral theories in light of analogies drawn from how a family works or ought to work (Metz, 2007; Behrens, 2011). Furthermore, a scholar like Augustine Shutte who defends a 'Thomist' understanding of ubuntu observes that a family is seen in the African tradition as intrinsically good (2001: 29). In this light, Mogobe Ramose, an expert on Ubuntu, comments:

According to this understanding of the family, it is unethical to withhold or to deny botho/ubuntu towards a member of the family, in the first place, and the community at large. In other words, charity begins at home (Ramose, 2003: 386).

This observation by Ramose interestingly informs us that Ubuntu as a moral theory demands that one prioritise one's extant relations, specifically, family, before one can extend one's moral concerns to a wider society. In another place, he introduces the idea of partiality by using the idea of permeable boundaries since he is opposed to what he calls 'bounded reason'. He states: "Thus motho ke motho ka batho is the maxim that prescribes permeable boundaries" (2003: 330). It is interesting that whatever else this comment amounts to, it begins by validating boundaries, thus affirming partiality; but, insightfully, he further informs us that the boundaries in question are permeable. In other words, one is urged to avoid moral myopia and parochiality by thinking that one's partialist considerations exhaust what morality is all about. A moral agent must recognise that she is not only her own person and a member of a family; moreover, she is also a member of different communities: her tribe, nation, country, continent and the world. It is for this reason that her moral sensitivity and sensibility must be as wide as the world is, but all this 'wide' moral responsibility must be interpreted from an agent's locus of focus, that is, from a perspective that is entirely her own. Simply put, though she has immediate duty to herself and family, all things equal, she also has a duty to the community (humanity) at large. 


\section{2 'Ancestors' and partiality}

It is not only the high prize attached to the family that buttresses the view that African ethics is best read as partialist. Another interesting source for defending a partialist thesis is the ubiquitous practice of ancestor veneration among African communities. Ramose informs us that "[t]he concept of community in the African philosophy of Ubuntu (Botho - humanness) is comprised of three tiers, namely, the living, the living-dead ('ancestors') and the yet to be born. Life is salubrious and just if harmony prevails in these tiers of community (2010: 300). On this view, one can't sufficiently talk of an African community until they have spoken about ancestors or the living-dead. The 'living-dead' are not 'gods', as in entities to be worshipped; strictly speaking, they are human 'persons' who have since joined a supernatural realm of God because they have lived morally worthy lives (Menkiti, 2004: 327). Precisely because they are 'persons', it is inappropriate and a sign of confusion to speak of 'ancestor worship' - hence it is appropriate to talk of ancestor veneration/reverence (Menkiti, 2004: 327). One interesting aspect of this tradition is that it functions within a partialist framework:

The other principal rule of action relates to ancestor worship. This is also based on the community of blood. It is a kind of worship that exclusively involves people of the same blood. And the main objective of the worship is to implore the help of the ancestors to send away all misfortunes that threaten their descendants (Kagabo, 2004: 238).

I will excuse Kagabo for incorrectly talking about ancestor 'worship'. Nevertheless, he rightly captures the idea that ancestor veneration typically functions within blood relations, or, specifically, family in an extended sense. It is for this reason that some ancestor rituals only involve family members, or that even if the whole community is involved, some parts of the ritual are held in private. It is this partialist consideration from the ubiquitous ancestor veneration I wanted to bring to the fore. I am appealing to this idea of ancestors since it is a commonly held view that extra-human beings reinforce morality (Ramose, 1992: 145; Gyekye, 2010).

Thus far, I have roughly discussed two aspects of African culture that somehow lend evidence to the idea that African moral thought is best interpreted as partialist. I proceed now to make my argument for partiality by considering the concept of personhood. 


\subsection{Personhood and partiality}

I now make an argument to the effect that African moral thought is best construed in terms of partiality. One central notion in African morality is that of 'personhood'. The notion of 'personhood' in this instance is normative insofar as it is a claim about what constitutes a good person or a moral exemplar i.e. a human being characterised by moral virtue (Menkiti, 1984; Wiredu, 2014). This notion of personhood is concerned with how one has conducted oneself relative to the relevant moral norms and standards; it evaluates one as a moral agent (Behrens, 2013: 105-107). It is this sense of personhood that appears to characterise African moral thought.

The notion of personhood I am appealing to here is generally considered to be a fundamental or defining feature of African moral thought (Masolo, 2010: 138). It is also interesting to note that a talk of personhood which implies a perfectionist or self-realisation ethics is reported to be a dominant interpretation of ethics (Metz, 2007: 331). With regards to this notion of personhood Gyekye states:

In Akan cultures, then, much is expected of a person in terms of the display of moral virtue. The pursuit or practice of moral virtue is held as intrinsic to the conception of a person. The position here may thus be schematized as: for my $p$, if $p$ is a person then $p$ ought to display in his conduct the norms and ideals of personhood. Thus, when a person fails to exhibit the expected moral virtues in his conduct, he is said not to be a person (1992: 109).

It is not enough to be a human being; more is expected from an African moral perspective - one ought to be a good person. A human being is here naturally construed as having an ability to form a good character. Metz corroborates this view when he observes that:

Personhood, selfhood, and humanness in characteristic subSaharan worldviews are value-laden concepts. That is, an individual can be more or less of a person, self, or human being, where the more one is, the better. The ultimate goal of a person, self, or human in the biological sense should be to become a full person, a real self, or a genuine human being, i.e., to exhibit virtue in a way that not everyone ends up doing (2010: 83).

What captures my attention in the above quote is that as much as everyone is believed to have the moral capacity to exhibit some virtues, not everyone ends up doing so. In other words, some people fail to reach the status of being moral exemplars. In fact, in this regard Menkiti states: "One conclusion appears inevitable, and it is to the effect that personhood is the sort of thing which has to 
be achieved, the sort of thing at which individuals could fail" (2004: 326). Thus, a society will be composed of those who have failed to live a truly human life and those who have succeeded. And those who have failed will be blamed and those who have succeeded will be praised (Darwall, 1977: 36-37).

If it is true, that this idea of one leading a genuine human life is an essential part of African moral thought, it appears to be taking us in a direction that is different from that of impartiality as suggested by Wiredu. When we make a moral judgement that one is a person, we are praising her for internalising sociomoral norms of a society and when we say she is not a person we are blaming her for failing to internalise these norms to inform her character. At the heart of this judgement is the recognition of an individual's effort. We are praising or blaming her for a certain moral exertion; her moral judgement singles her out individually as a (moral) achiever or not. Community approval is a response to her (own) achievement; she made it, morally speaking. It is her achievement and (in some important sense) not that of a community - the community just recognises and acknowledges and praises her. This partialist reading of personhood finds expression and support from a singularly unexpected source: Wiredu:
What, then, in its social bearings, is the Akan ideal of personhood? It is the conception of an individual who through mature reflection and steady motivation is able to carve out a reasonably ample livelihood for self, family, and a potentially wide group of kin dependents, besides making substantial contributions to the well-being of society at large. The communalistic orientation of the society in question means that an individual's image will depend rather crucially upon the extent to which his or her actions benefit others than him/herself, not, of course, by accident or coincidence but by design. The implied counsel, though, is not one of unrelieved self-denial, for the Akans are well aware that charity further afield must start at home (Wiredu, 1992: 200).

This passage is one which is supposed to shake Wiredu from his slumber of defending an untenable position of impartiality. It is obviously at odds with his moral principle of sympathetic impartiality - I suspect he is not aware of this tension. Wiredu is very clear that one becomes a good person as a result of some personal exertion to improve one's (own) life. In this sense, a journey to moral perfection is a personal project, a partialist consideration, within the incubator of social context (Menkiti, 2004: 326). It is important to note also that Wiredu appears to be suggesting that one owes immediate (more) duty to selfdevelopment then to one's family and, if possible, one can benefit a wide group. Then the observation that 'charity further afield must start at home' rubber- 
stamps the partialist reading of an African moral tradition - as much as one has a duty to the community at large, that duty must be interpreted within the prism of partiality, which prioritises one's personal projects, family, friends and so far as is possible one can extend one's reach and help to the community at large.

This argument can be stated simply in this fashion:

P1: If a moral theory is truly African then it must cohere with the centrally defining feature of African moral thought, personhood, which is partialist.

P2: Wiredu's sympathetic impartiality (and, any impartiality) does not cohere with the notion of personhood since that implies partiality

P3: Therefore, it is not a truly African moral theory

One possible objection against partiality might be that this reading of African ethics is individualist, whereas African thought is dominantly construed as communitarian. In this light Metz observes that one "finds contemporary African thinkers railing against Western "brash competitiveness," "single-minded commercialism," "unbridled individualism," and "morally blind, purely economic logic," instead tending to favour certain kinds of cooperatives" (2007: 326). Furthermore, Gessler Nkondo, commenting on ubuntu, refers to "the supreme value of society, the primary importance of social or communal interests, obligations and duties over and above the rights of the individual" (2007: 90). This position is sometimes captured as the ontological priority of the community over the individual (Menkiti, 2004: 324; Nkondo, 2007: 90). The objection here is that the idea of partiality leans towards an individualist interpretation of African culture and moral thought, which is supposedly at odds with an African culture and moral thought that emphasises the slogan of a community first.

I think, first of all, that it is important that we clarify two senses of the claim that African ethics is not 'individualist'; much of the criticism in this direction conflates this distinction. On the one hand, one can use the notion of 'individualism' to make a descriptive claim about how persons come to form their identities, and the role played by social relations (community) in this process (Neale \& Paris, 1990: 425-526). This is a descriptive claim about the relationship between an individual and a community (Wiredu, 2008: 336). On the other hand, one can make a claim about the location of moral value as internal in the individual (Behrens, 2011: 18), and this in environmental ethics is typically contrasted with 'holism', which locates value in the group (Metz, 2011: 388).

For the first kind of 'individualism' one is making claims that are anthropological or about social-customary arrangements, specifically, contingent facts about how 
to organise society and formations of individual identities. ${ }^{8}$ In this light, Wiredu observes, African societies are 'communitarian' in the sense that they prioritise what we owe to each other in terms of obligations (2008: 336). And, he is quick to remind us that some cultures are individualistic and some communitarian; all this talk is a matter of degree (2008: 335).

These corrective and moderate understandings of community by Wiredu, I suspect, are strongly influenced by his colleague Kwame Gyekye. Gyekye argues for what he calls 'moderate communitarianism'. His first and foremost aim is to reject what he calls 'extreme communitarianism' insofar as it does not have space for (individual) human rights - rights are things that belong to individuals qua individual (Gyekye, 2007: 39). His moderate view balances the ideal of individuality (dignity) and that of community (common good) (1992: 113; 2007: 41). With regards to the latter it calls for a common good, and with regards to the former it demands that individuals be given certain rights that belong to them naturally and it further calls for enough space for individuals not to be wholly consumed by a community, thus to pursue their own projects and such like (1992: 114). I observe that Gyekye also conflates the two senses of 'individualism' as adumbrated above, but on the whole is correct to defend a space for an individual and her rights, without jettisoning her social obligations. I therefore observe that something like moderate communitarianism that balances individual interests and collective interests is compatible with partiality.

Furthermore, with regards to the second sense of 'individualism' as a claim about the location of moral good in the individual, it is interesting to note with Metz that much of African ethics is actually individualist insofar as it locates the good in some (internal) individual property, be it life or dignity or self-realisation. In fact, Metz shows that the literature is dominated by individualist interpretations of ethics: out of six, only two principles of right action base morality on some relational property, the rest base it on some individualist consideration, be it dignity, life, utility or perfection (Metz, 2007: 333). It is therefore simplistic and not obviously true to claim that African ethics are not individualist.

A friend of impartiality might further argue that partiality is incompatible with the oft reported hospitality and kindness of Africans to complete strangers, which appears to be a consideration that is best explainable by impartiality. The partiality I defend here has resources to respond to this concern. Partiality as a substantive claim does not entail that we should not help strangers, it is merely asserting that we owe more to those close to us than those not. Thus, to advocate partiality

8 I find Neale's et all (1990: 423 - 430) discussion about 'individualism' qua "contingently shared relations" and communitarianism qua essentially shared relations to be lucid. They are very clear that these are descriptive and not normative claims. 
is not tantamount to rejection of hospitality to strangers. To advocate partiality is not to deny the equality of human beings; it is rather to deny that equality of human beings amounts to same treatment of all human beings without any positive discrimination. Metz responds to this charge of incompatibility between partiality and hospitality to strangers by pointing out that "Ubuntu similarly defends the value of partiality - I owe more to family than to nonfamily - but it also emphasizes the obligations we owe to strangers, simply in virtue of their humanity" (2001: 89).

The fact that Africans prioritise extant and close relationships more than nonclose and possible relationships does not mean that we ignore or become cold to the humanity of others when in need. The fact of their humanity is sufficent ground to respond to them accordingly. It is for this reason (of our shared humanity) that Ramose postulates permeable boundaries, and this postulation makes an African conception of partiality rich since it allows us to extend beyond family web and other special relationships, wherever possible. The insight here is that we can never fully respond to the plight and unfortunate condition of strangers and wayfarers on our doorstep in need until we have exposed ourselves fully to the plight of those close to us. We can never say we love humanity until we have been true to it with those close and special to us. Hence charity begins, but note, it does not end there.

\section{Conclusion}

In this discussion, I have critically reflected on Wiredu's moral theory at two levels, as a meta-ethical theory (humanism) and as a theory of right action (sympathetic impartiality). I problematised one of the stubborn features of African moral features that renders morality in terms of human interests or any other (human) feature. I suggested that a more promising moral theorisation must take us in the direction of non-anthropocentrism. This is where moral theorisation should be going. Unfortunately, as things stand in the literature, much of it is humanistic. I also rejected humanism to open up a space for a robust philosophical (theological) ethics in the African tradition given that humanism is not as firmly grounded as Wiredu (and others) would have us think. I have also problematised impartiality as a central feature of African moral theorisation; I did this so we can have extensive philosophical works that do more research on African ethics in this regard. The debate between partiality and impartiality has not been extensively considered in the African moral tradition; I have suggested some useful places to start such an investigation. 


\section{Bibliography}

BEHRENS K (2011) African philosophy, thought and practice and their contribution to environmental ethics. Johannesburg: University of Johannesburg.

BeHRENS K (2013) Two "normative" conceptions of personhood. Quest 25: 103-118.

DARWALL S (1977) Two kinds of respect. Ethics 88: 36-49. http://dx.doi. org/10.1086/292054

DonNelly J (1982) Human rights and human dignity: an analytic critique of non-western conceptions of human rights. The American Political Science Review 76: 303-316. http://dx.doi.org/10.2307/1961111

DzoBo K (1992) Values in a changing society: man, ancestors and God. In: Gyekye K \& K Wiredu (eds) Person and community: Ghanaian philosophical studies, 1. Washington DC: Council for Research in Values and Philosophy.

GYEKYE K. (2004) Beyond cultures: perceiving a common humanity, Ghanaian philosophical studies. Accra: The Ghana Academy of Arts and Sciences.

IMAFIDON E (2013) On the ontological foundation of a social ethics in african traditions. In: Imafidon E \& J Bewaji (eds) ontologized ethics: new essays in african meta-ethics. New York: Lexington Books.

KoRsGAARD C (1983) Two distinctions in goodness. The Philosophical Review 92: 169-195. http://dx.doi.org/10.2307/2184924

Louw D (2004) Ubuntu and the challenges of multiculturalism in post-apartheid south africa. Utrecht: Centre for Southern Africa.

MANYELI L (2010) A re-reading of gyekye's moderate communitarianism. Lwati: A Journal of Contemporary Research. No pages.

MASOLO D (2010) Self and community in a changing world. Bloomington: Indiana University Press.

MBITI J (1970) African religions and philosophy. New York: Doubleday.

MENKITI I (1984) Person and community in traditional african thought. In: Wright L (ed) African Philosophy, An Introduction. Lanham, MD: University Press of America. No pages.

MENKITI I (2004) On the normative conception of a person. In: Wiredu, K (ed) companion to african philosophy. Oxford: Blackwell Publishing.

METZ T (2010) human dignity, capital punishment and an african moral theory: toward a new philosophy of human rights. Journal of Human Rights 9: 81-99. http://dx.doi.org/10.1080/14754830903530300

METZ T (2012) Developing african political philosophy: moral-theoretic strategies. Philosophia Africana 14: 61-83. http://dx.doi.org/10.5840/ philafricana20121419

Metz T (2013) Two conceptions of african ethics in the work of D.A. Masolo. Quest 25:141-161. 
MKHIZE N (2008) Ubuntu and harmony: an african approach to morality and ethics. In: Nicolson R (ed) persons in community: African ethics in a global culture. Pietermaritzburg: University of KwaZulu-Natal Press.

NKONDO G (2007) Ubuntu as public policy in South Africa: a conceptual framework. International Journal of African Renaissance Studies 2: 88-100. http://dx.doi. org/10.1080/18186870701384202

OKEJA U (2013) Normative justification of a global ethic: a perspective from African philosophy. New York: Lexington Books.

RAMOSE M (1992) African democratic tradition: oneness, consensus and openness: a reply to Wamba-dia Wamba. Quest 6: 62-83.

RAMOSE M (2009) towards emancipative politics in Africa. In: Murove F (ed) African ethics: an anthology of comparative and applied ethics. Pietermaritzburg: University of Kwa-Zulu Natal Press.

RAMOSE M (2009) ecology through ubuntu. in: murove f (ed) African ethics: an anthology of comparative and applied ethics. Pietermaritzburg: University of Kwa-Zulu Natal Press.

SHUTte A (2001) Ubuntu: an ethic for a New South Africa. Pietermaritzburg: Cluster Publications.

SUMNER L (1996) welfare, happiness, and ethics. Oxford: Clarendon Press.

TEFFOJ(2004)democracy, kingship, and consensus: A South African perspective. In: Wiredu K (ed) Companion to African philosophy. Oxford: Blackwell Publishing.

WAMALA E (2004) government by consensus: an analysis of a traditional form of democracy. In: Wiredu K (ed) Companion to African philosophy. Oxford: Blackwell Publishing.

Wingo A (2004) Fellowship associations as a foundation for liberal democracy in Africa.

IN: WIREDU K (ed) Companion to African philosophy. Oxford: Blackwell Publishing. WIREDU K (2005) On the idea of a global ethic. Journal of Global Ethics 1: 45-51. http://dx.doi.org/10.1080/17449620500106636

WIREDU, K (1992) moral foundations of an African culture. In: Wiredu K \& K Gyekye (eds) Person and community: Ghanaian philosophical studies, 1. Washington DC: The Council for Research in Values and Philosophy.

WIREDU K (1996) Cultural universals and particulars: an African perspective. Indianapolis: Indiana University Press.

WIREDU K (1996) Reply to English/Hamme. Journal of Social Philosophy 27: 234243. http://dx.doi.org/10.1111/j.1467-9833.1996.tb00248.x

WIREDU K (1999) Society and democracy in Africa. New Political Science 21: 33-44. http://dx.doi.org/10.1080/07393149908429850

WIREDU K (2008) Social philosophy in postcolonial africa: some preliminaries concerning communalism and communitarianism. South African Journal of Philosophy 27: 332-339. http://dx.doi.org/10.4314/sajpem.v27i4.31522 